\title{
The Use and Abuse of Graphs in Annual Reports: Theoretical Framework and Empirical Study
}

\author{
Vivien Beattie and Michael John Jones*
}

\begin{abstract}
This study investigates the use and abuse of graphs in external financial reporting. From an analysis of the annual reports of 240 large UK companies for the year ended 1989 we document the nature and extent of graph usage. The average number of graphs per annual report is 5.9 , with $65 \%$ of companies graphing at least one key financial variable. Drawing on modern theories of graphical perception we identify selectivity in the use of graphs, and non-compliance with the principles of graph construction, as potential distortions in the communication process. We find that companies with 'good' performance are significantly more likely to use financial graphs. Material measurement distortions occur in $30 \%$ of these graphs, with the underlying numerical data being exaggerated by an average of $10.7 \%$. We conclude that auditors' and directors' responsibilities in this area should be made more explicit.
\end{abstract}

\section{Introduction}

There has been no systematic study of the use, and possible abuse, of graphs in the annual reports of UK companies. This is surprising since it is frequently suggested in the professional accounting press and journals that graphs can aid in the communication of accounting information (Holmes, 1984; Cunningham, 1990; Hussey, 1990). It is also suggested, however, that graphs can be misleading and a number of examples, resulting from casual empiricism, have received publicity (see, for example, Leach, 1985 and 1988; Lea, 1989; Sugden, 1989; Wood, 1990).

The potential for graphs to improve the effectiveness of communication in external financial reporting is readily established. Surveys of shareholders' use of annual reports consistently indicate that, although the annual report is a primary information source, it is not read thoroughly (Lee and Tweedie, 1975 and 1977, provide evidence for

*The authors are lecturers in accounting at the University of Southampton and the Cardiff Business School, respectively. They gratefully acknowledge the financial support of the Chartered Association of Certified Accountants. The empirical evidence reported in this paper is drawn from the authors' much larger research study of selectivity, measurement and presentation issues in UK corporate annual reports which is reported in the Chartered Association of Certified Accountants' Research Report, 'The Communication of Information using Graphs in Corporate Annual Reports'. The authors also thank, for their helpful comments, colleagues at the Universities of Cardiff and Southampton, particularly Michael Bourn, Dick Edwards, Maurice Pendlebury, Mick Silver and Charles Sutcliffe; the two referees of this paper; and participants at the 1991 British Accounting Association Conference and the 1991 British Academy of Management Conference. the UK; for a summary of studies worldwide see Hines, 1982). In these circumstances the graphs contained in annual reports, being visually appealing, are most likely to be noticed. Furthermore, since the human capacity to remember visual patterns is superior to memory for text or numerical tabulations, graphs are also most likely to be remembered (Paivio, 1974, summarises several studies). Graphs are also known to be particularly useful for highlighting trends (e.g. Wright, 1989).

It is possible, however, for graphs to introduce distortions into the communication process which mislead the recipient. There are two principal causes of distortion: selectivity of some form, and non-compliance with the principles of graph construction. Selectivity, at its most fundamental level, involves the decision whether or not to use graphs. If they are used, then there may be further selectivity in the particular choice of financial variables graphed. ${ }^{1}$ The need for graphs in annual reports to reflect a number of indicators and not simply one or two which are particularly favourable to the company has been recognised by Wilkins and Lennard (1988) and Mason (1985).

Having made the decision to portray certain variables graphically, the second way for distortion to arise lies in the construction of the graphs themselves. The graphics literature has provided a number of informally derived principles of graph construction. A number of cases where these prin-

'Other forms of selectivity, such as the length of time series reported, and the precise definitional form of the variables, are not considered in this study. They form the basis of a separate research study. 
ciples have been violated are documented by casual empiricism. Leach (1988) illustrates the misleading effect of incorrectly scaled axes with reference to the reports of Asda-MFI and Allied-Lyons. AsdaMFI's profit had increased by $136 \%$ between 1982 and 1986, but a histogram representing this variable increased by $330 \%$; while Allied-Lyons' net assets per share rose by $86 \%$, yet a representational histogram increased by only $61 \%$. Sugden (1989) refers specifically to the use of non-zero vertical axes to enhance apparent rates of growth, a practice used by Witan Investments to illustrate the growth of net asset value in their results announcement of 1989.

These examples of selectivity and graph distortion may provide illustrations of active information manipulation. In their review of the literature on information manipulation, Birnberg, Turopolec and Young (1983, pp. 120-122) identify biasing (selection of favourable signals) and focus ing (enhancement/degradation of aspects of the information set) as types of dysfunctional behaviour. Certainly strong incentives exist for management to manipulate the message received by annual report users. In recent years the widespead use of creative accounting techniques has been extensively documented and criticised (Griffiths, 1986; Tweedie and Whittington, 1990; UBS Phillips and Drew, 1991).

The effects of graph use and distortion in the context of external financial reporting are largely unexplored. The limited findings available suggest that users' perceptions are affected by distortions (Taylor and Anderson, 1986). There are, however, a considerable number of experimental studies which focus on the effect of graph use on the decision-effectiveness of managers and auditors. The rationale for these empirical studies arises from the identification of presentation format as a key information processing variable which affects the decision process (Libby and Lewis, 1977, pp. 246-7). Recent findings indicate that the effect of graphical format is contingent upon decision task (Blocher, Moffie and Zmud, 1986; Sullivan, 1988; Kaplan, 1988; De Sanctis and Jarvenpaa, 1989; and Davis, 1989).

The purpose of the present study is to conduct the first systematic empirical investigation of the use and abuse of graphs in UK annual reports. The three main research objectives are: (1) to establish the nature and extent of graph usage, (2) to identify and analyse instances of non-compliance with the principles of graph construction, and (3) to investigate the relationship between the incidence of graph use and abuse, and measures of corporate performance.

The remainder of this paper contains five sections. In the first section we review the extant statistical graphics literature, in order to identify those principles of graph construction which have a rigorous theoretical base. Section two provides a critical appraisal of studies which deal with the use of graphs in an accounting context and generates hypotheses. A brief outline of the methods used is given in section three. Our results are presented in section four, together with a discussion. The final section summarises and discusses the policy implications of our results.

\section{Statistical graphics literature}

This literature recognises that graphs are used in two fundamentally different ways: to analyse data and to present/communicate information to an audience. In the present study, the primary function of graphs in the annual report is taken to be the communication of information, and therefore it is only this branch of the literature which is considered in this section. Two phases in the development of the statistical graphics literature can be distinguished. Initially, principles of graph construction were inductively derived from practice; more recent studies have attempted to establish these principles within a rigorous theoretical framework. These recent studies introduce a distinction between the visual and cognitive tasks involved in the process of graph perception, a distinction which we argue is of particular importance where graphs are used for presentation rather than analysis. This section briefly reviews the relevant theory and empirical findings of these two phases. Much of the recent literature has not previously been introduced to the field of accounting.

The statistical graphics literature emerged in an ad hoc, informal way in response to the need for higher standards of design. Although attention had been drawn to poorly designed and misleading graphs, appearing in a wide variety of publications, as early as the 1950s (Huff, 1954), it is only comparatively recently that the issues and problems have received significant consideration. Gradually, a set of design and construction principles was derived from the distillation of best practice (Schmid and Schmid, 1979; Schmid, 1983; Tufte, 1983). The primary function of this set of principles was the "creation of a model or schema in the form of a well-ordered and efficient graphic structure for the purpose of transmitting by visual communication a body of statistical data' (Schmid, 1983, p. 3).

The main types of graph used in the communication of quantitative information are line, bar/

\footnotetext{
2The label 'bar graph' is frequently applied to both bar and column graphs, however a meaningful distinction does exist (Schmid, 1983, p. 38). The bar graph is appropriate for comparisons of descriptively labelled, horizontally arranged, categories. The column graph is suitable for time series, with the columns arranged vertically. In this study, since the overwhelming majority of graphs reflect time series, the term "column graph' is used throughout.
} 
column, pie and pictorial. ${ }^{2}$ In each case, the fundamental principle of graph design is that the representation of numbers, as physically measured on the surface of the graph itself, should be directly proportional to the numerical values of the variables being represented (Tufte, 1983, p. 56). We refer to violations of this principle as measurement distortion. ${ }^{3}$ The physical measure involved will depend upon the type of graph in use, viz., distance from origin (line graphs), height of column (column graphs). Violations of this fundamental principle can be measured by comparing the ratio of the size of the graphic effect with the size of the numerical effect, using Tufte's 'lie factor' (1983).

Measurement distortion can be attributable to specific causes, such as a non-zero axis, a broken axis, or a non-arithmetic scale. These graphic techniques represent departures from a graph's basic structural characteristics - departures which the user may fail to notice and/or understand. In the case of line and column graphs (the most common types of graphs encountered), the basic structure comprises coordinate axes, formed by the intersection of two perpendicular lines. Each axis is scaled in equal units from the origin, and grid lines facilitate the accurate reading of the values represented. As comparisons are based on direct linear values it is essential to include a zero referent line, since 'the origin of the two axes in Cartesian space is usually the same point' (Kosslyn, 1989, p. 208). A broken axis or a non-arithmetic scale also results in distortion, since equal distances along the axis do not represent equal amounts (Schmid and Schmid, 1979). Measurement distortion need not, however, be attributable to a specific cause - the graph may simply not be constructed such that distance is proportional to numerical values.

In recent years the growing use of computer graphics has served as a catalyst in the development of a theoretical framework for statistical graphics. Experiments in graphical perception have been conducted, which draw on the foundation disciplines of statistics, psychology, psychophysics and cartography. Formal theories of graphical perception have now been developed, in which the process of extracting quantitative information is characterised as consisting of visual and cognitive tasks. Elementary visual tasks involve the perception of slope (for line graphs) or distance (for column graphs), while the higher level cognitive tasks include reading scale values, performing mental calculations, and reasoning.

Cleveland and his associates concentrate on the elementary graphical perception tasks, to which

\footnotetext{
${ }^{3}$ Misperception due to non-compliance with the principles of graph construction may be caused by a number of factors other than measurement distortion, which may be collectively termed presentational distortion. These issues form the subject of a separate study by the authors.
}

they apply the theory of visual perception (see, for example, Cleveland and McGill, 1987). Extensive use is made of two laws from sensory psychophysics. These laws imply that the absence of common, aligned scales, with grid lines, will impair the judgement of magnitudes, and that graphs requiring judgements of length can be expected to be more accurately perceived than those requiring judgements of area, volume, angles or slopes. These predictions are confirmed in experimental studies (Cleveland, 1985, ch. 4; Lewandowsky and Spence, 1989).

Other writers have emphasised the higher level cognitive tasks in graphical perception to a greater extent, to which they apply theory from cognitive psychology (Kosslyn, 1985, 1989; Simkin and Hastie, 1987). Kosslyn (1989) develops a scheme for analysing the communicative effectiveness of graphs at three levels: syntactic, semantic and pragmatic. The model focuses on the basic components of the graph (coordinate axes, labels, etc.), and specifies their interrelations at the various levels of analysis. Effective communication requires that the graph does not violate 'acceptability principles' at any of these levels. Kosslyn's scheme for the evaluation of graphs is broader than that of Cleveland.

Where the primary function of graphs is presentation, we argue that the visual information processing of graphs is likely to be largely confined to the elementary visual tasks. In such circumstances, the scales and labels of axes may not be thoroughly read and cognitively processed, and the final meaning conveyed will depend primarily on the visual aspects of the graph. The existence of measurement distortion thus becomes of prime significance.

\section{The accounting context: hypotheses generation}

To date most studies of the use of graphs in an accounting context have focused on their use in data analysis. However, a few writers have considered the role played by graphs in the communication of financial information to shareholders. The majority of these studies briefly allude, on the basis of casual empiricism, either to the increasing frequency of graphs within corporate reports (e.g. Mason, 1985; Wilkins and Lennard, 1988), or to the importance of graphs for good corporate design (e.g. Martin, 1989), or to examples of graph abuse (see Introduction). In addition, a number of studies seek to identify general guidelines for graph construction from the informal statistical graphics literature (Jarett, 1983; Anderson, 1983; and Holmes, 1984).

Taylor and Anderson (1986) develop and synthesise seven guidelines for the preparation of graphs which are consistent with the financial 
statements. They also experimentally examine the effect of violations of these guidelines on perceptions of company performance, using commercial bank loan officers. They conclude that faced with graphs distorted to give a more favourable impression, the loan officers' perceptions also became 'far more favourable' (p. 127). Korol (1986) provides a rigorous discussion of graph perception in the context of external financial reporting, introducing the statistical graphics theory based on visual perception.

We know of only three studies which conduct empirical investigations. First, Sugden (1989) provides examples of a number of misleading graphic practices contained in UK annual reports. Second, Johnson, Rice and Roemmich (1980) examine fifty annual reports for the years 1977 and 1978 taken at random from the Fortune 500. Out of a total of 423 graphs they identify $125(29 \%)$ as being 'improperly constructed'. Their sample size is small, however, and they do not quantify the degree of measurement distortion.

In the third and most authoritative study to date, Steinbart (1989) examines 319 annual reports for 1986 from the Fortune 500, finding that 252 companies $(79 \%)$ include graphs. He focuses on the quantification of measurement distortion in graphs of three key financial variables (sales, net income, and dividends) and relates this to the change in net income over one year. Based on 698 graphs of these variables, he discovers an average measurement distortion of $+11 \%$. He also finds that discrepancies which are favourable to the company are significantly more likely to occur in the annual reports of companies which experience a decline in net income.

Steinbart's (1989) study is the first to quantify the extent of measurement distortion and investigate how corporate performance is related to the use of graphs and the incidence of measurement distortion. His study does, however, have a number of limitations. First, the use and distortion of sales and dividend graphs is related to the change in net income, rather than the change in the variable being graphed. A priori, it is not clear which, if either, will be the dominant influence on the decision to use, or distort, graphs. Further, these indicators may move in different directions (e.g. sales increase combined with a decline in net income), in which case the relationships become confounded. Second, corporate performance is proxied using the directional change in net income, without taking into account the magnitude of the change. Third, by focusing on corporate performance over one year only, the influence of the trend is ignored. Finally, given the different business environment, regulatory system and accounting practices found in the US (e.g. Carsberg, 1985; Nobes, 1987), different findings may emerge in a UK context.

\section{Hypotheses}

Four research hypotheses were developed from our consideration of the statistical and accounting graphics literatures. These extend the approach adopted by Steinbart (1989). Hypotheses 1 and 2 concern the use of graphs:

Hypothesis 1: Graphs of key financial variables are more likely to be included in the annual reports of companies with 'good', rather than 'bad', performance in terms of earnings per share and profit before tax as profit indicators.

Hypothesis 2: Graphs of key financial variables are more likely to be included in the annual reports of companies with 'good', rather than 'bad', performance in terms of the variable graphed.

Hypotheses 3 and 4, developed with reference to the information manipulation literature, concern the effect and incidence of measurement distortion:

Hypothesis 3: Measurement distortion is likely to give a more, rather than less, favourable portrayal of the company's performance.

Hypothesis 4: Favourable measurement distortion is more likely to occur in the annual reports of companies with 'bad', rather than 'good', performance in terms of the variable graphed.

In testing these hypotheses, alternative time periods were examined (current year and five years), and alternative bases for classifying performance as 'good' or 'bad' were used (zero cut-off and comparison with average performance across the sample).

\section{Methods}

\section{Sample Selection}

A sample of 250 companies was taken from the largest (by market capitalisation) 500 listed UK companies as at 31 March 1989 (Stock Exchange, 1989). Every second company was selected. Requests were made, by letter, for each company's 1989 annual report. After extensive follow-up, ten companies were eliminated for a variety of reasons, leaving a sample of 240 annual reports. ${ }^{4}$

\section{Research Instrument}

A data collection sheet was designed with reference to the statistical and accounting graphics and information manipulation literatures. It was then piloted and revised. Data on graph usage, aspects

\footnotetext{
${ }^{4}$ The reasons for elimination from the sample were: annual report not yet filed (one company), annual report not published as company is a wholly-owned subsidiary (one company), takeover (two companies), status changed to private company (one company), no trend data due to reorganisation (two companies), and non-respondents (three companies).
} 
of graph design and construction, and company performance in terms of key financial variables were extracted. In particular, details concerning the degree of measurement distortion and its specific causes were collected. ${ }^{5}$ The data were then coded, and transferred to a database. Subsequent statistical analysis was conducted using SAS.

\section{Index of Measurement Distortion}

To facilitate our analysis of measurement distortion a graph discrepancy index was calculated (an adaptation of Tufte's lie factor first suggested by Taylor and Anderson, 1986):

$$
\text { Graph Discrepancy Index }=\left(\frac{a}{b}-1\right) \times 100 \% \text {, }
$$

where

$$
\begin{aligned}
a= & \text { percentage change (in cms) depicted in } \\
& \text { graph, i.e. } \\
& \frac{\text { height of last column }- \text { height of first column }}{\text { height of first column }} \\
& \times 100 \%
\end{aligned}
$$

$b=$ percentage change in data.

In the absence of measurement distortion, the index is zero. Positive (negative) values of the index indicate the percentage by which the trend in the data is exaggerated (understated) by the graph. ${ }^{6}$ This interacts with the direction of the trend in the data to determine if the effect of the distortion is favourable to the company or not. The exaggeration of an upward trend and the understatement of a declining trend both give more favourable impressions of a company's performance.

An illustration of favourable exaggeration is given in Figure 1. Panel A is accurately plotted, while panel B overstates the increase in the data by $25 \%$. Inaccuracies of this type, resulting from inaccurate plotting, are greatly facilitated by the lack of a scaled vertical axis and/or grid lines. Other causes of distortion can frequently result in distortions of much greater magnitude.

\section{Results}

The general pattern of graph use is shown in Table 1: 189 companies $(79 \%)$ use graphs, with 156 $(65 \%)$ graphing at least one key financial vari-

\footnotetext{
${ }^{5} \mathrm{~A}$ copy of the research instrument is available from the authors upon request.

${ }^{6}$ It should be noted that this simple index of measurement distortion does not take into account the length of the time series graphed-a $25 \%$ distortion over two years is different from a $25 \%$ distortion over five years. There is no accepted method for dealing with this methodological problem. In the present study, however, since the majority $(72 \%)$ of the key financial graphs cover five years with the remainder being split almost equally between shorter (13\%) and longer (15\%) time periods, this is not a particular problem.
}

able - defined as the four most frequently graphed financial variables (turnover, profit before tax, earnings per share (EPS), and dividends per share (DPS)). We distinguished between financial and non-financial companies in our sample, since there are inherent differences in the structure of their financial statements. Our results show that whilst both types of company are equally likely to use some form of graphs, financial companies are less likely to include graphs of the key financial variables $\left(\chi^{2}=11.31, \mathrm{p}<0.001\right)$.

The total number of all types of graph, by type, is given in Table 2. Clearly column graphs are most popular. The average number of graphs contained in annual reports is 5.9, with the figure rising to 7.5 based on only those companies using graphs. Table 3 analyses all the topics graphed in the annual reports in descending order of frequency. Apart from key financial variables, by far the most commonly graphed topic by non-financial companies was segmental information for turnover and profit, the basis for segmentation being either business sector or geographical location. Piecharts showing the segmentation of an annual total were in many cases accompanied by time series graphs for the individual segments. The most common additional topic graphed by the financial companies was the composition of their asset portfolios. Overall, the table illustrates considerable diversity in the choice of topics graphed by companies. For example, 14 out of 240 companies have graphed capital expenditure, yet these constitute only $1 \%$ of the total number of graphs. Topics which constituted less than $1.0 \%$ of the total have not been shown separately.

From this point on, the discussion deals exclusively with graphs of the four key financial variables. Table 4 shows the types of graphs used for the key financial variables. The column graph is even more popular for this group of variables, representing $84 \%$ of all such graphs. The absence of pie graphs is due to their unsuitability for displaying time series. Chi-squared tests of the independence between the use of graphs and the classification of performance as 'good' or 'bad' are reported in Table 5. In all tests, the relationship was in the expected direction. Column one of panel A indicates that the decision to use graphs of key financial variables is affected by 'good' performance, measured as the direction of change in earnings per share (EPS), especially over the current year. To give a feel for the data underlying this $\chi^{2}$ test statistic of 18.80 , we can report that of the 183 companies in the sample whose EPS increased over the current year, $73 \%$ included graphs of at least one key financial variable, whereas only $41 \%$ of the remaining companies, whose EPS decreased, did so. The strength of this relationship, measured using the phi coefficient, is 0.28 , indicating a moderate association between the two variables. 


\section{Figure 1}

\section{Illustration of Measurement Distortion}

Graph Discrepancy Index $(\mathrm{GDI})=\left(\frac{a}{b}-1\right) \times 100 \%$.

With reference to panel B:

$$
\begin{gathered}
a=\frac{4.8-0.8}{0.8}(\mathrm{~cm}) \times 100 \%=500 \%, \\
b=\frac{50-10}{10}(£ \mathrm{~m}) \times 100 \%=400 \%, \\
\text { thus, GDI }=+25 \%
\end{gathered}
$$

$\varepsilon \mathrm{m}$

10

1

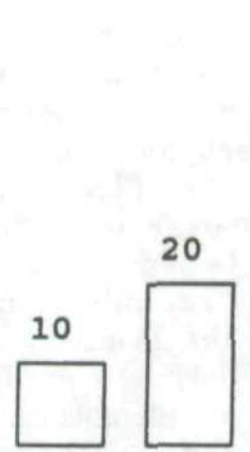

2
30

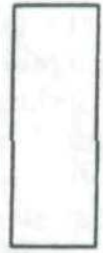

3
50

$\mathfrak{f m}$
40

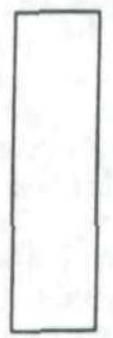

4

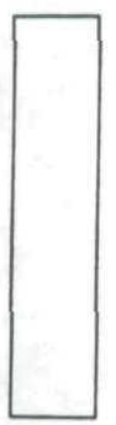

5
Year

panel A: Correct
1

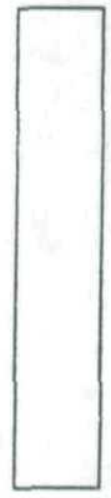

5

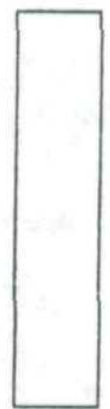

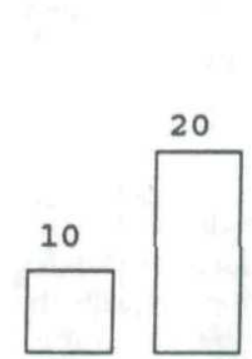

2

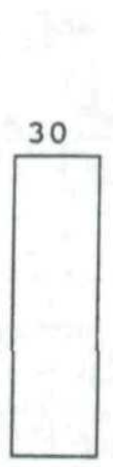

3

panel B: Incorrect

This association is significant at the $1 \%$ level based on the observed $\chi^{2}$ value of 18.80 .

The remaining columns in panel $\mathrm{A}$ reveal that for each of the individual variables (measured over one or five years), all associations are significant at the $1 \%$ level, with the one year results being marginally more significant. Tests were also run using profit before tax as a profit indicator-the results are marginally less significant and are not reported here. Hypothesis 1, which states that graphs of key financial variables are more likely to be included in the annual reports of companies with 'good' rather than 'bad' performance in terms of a profit indicator, is strongly supported.

\section{Table 1}

Use of Graphs in the Annual Reports of 240 Large Listed UK Companies

Variable graphed

Non-financial companies $(n=172)$

Any financial or non-financial variable

At least one key

financial variable:

turnover

profit before tax

earnings per share

dividends per share

$\begin{array}{rl}\text { No. } & \% \\ 136 & 79 \\ 123 & 72 \\ 82 & 48 \\ 107 & 62 \\ 108 & 63 \\ 91 & 53\end{array}$

\section{Financial} companies $(n=68)$

Total sample

$(n=240)$

$\begin{array}{rrrr}\text { No. } & \% & \text { No. } & \% \\ 53 & 78 & 189 & 79 \\ 33 & 49 & 156 & 65 \\ 9 & 13 & 91 & 38 \\ 24 & 35 & 131 & 55 \\ 19 & 28 & 127 & 53 \\ 25 & 37 & 116 & 48\end{array}$




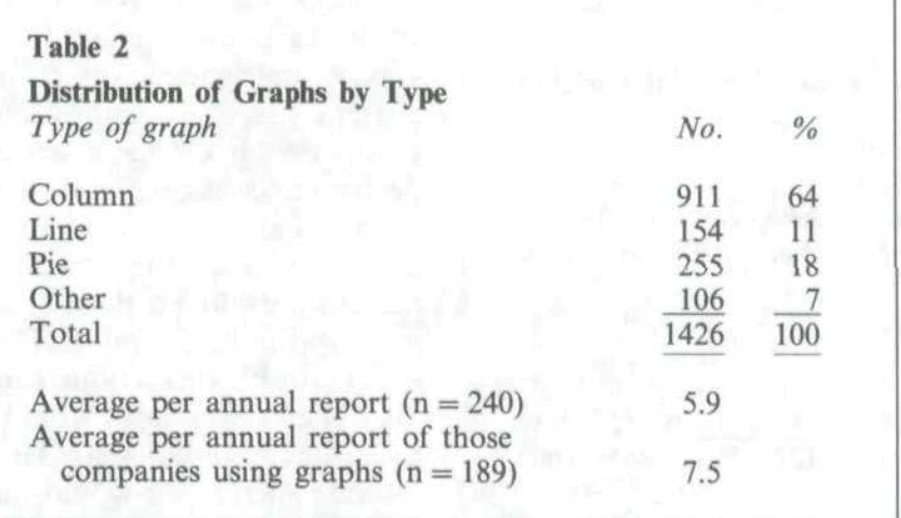

Panel B of Table 5 investigates hypothesis 2, i.e. whether the inclusion of graphs of key financial variables is associated with performance in terms of the graphed variable, rather than a general profit indicator. Based on performance over the current year, significant associations exist except, surprisingly, in the case of turnover graphs. We are currently unable to offer any explanation for this result for turnover graphs. Based on performance over five years, the associations were marginally less significant, except in the case of turnover graphs where the association now becomes significant. Hypothesis 2 is supported. In general, the results reported in Table 5 suggest that the decision to use graphs is significantly associated with both earnings performance and the graphed variable's performance. The current year's performance is more significant than the trend over five years.

In the tests discussed above, performance was classified as 'good' or 'bad' based on each company's position with respect to an absolute zero cutoff point. It seemed likely, however, that the magnitude of the performance indicators would also be relevant, assuming that management perceive their performance to be judged relative to other companies. In order to investigate this idea, we calculated the percentage change in each key financial variable over the current year, and used the median percentage change across the sample as a revised cutoff point. The median was used as the average measure, in preference to the mean, due to the highly skewed nature of the distribution. We then tested whether companies were more likely to

Table 3

Analysis of Graphs by Topic

465 key financial variables (in 27 cases

two key financial variables were shown on

the same graph)

Segmented turnover (time series)

Segmented profit (time series)

Segmented turnover (non-time series)

Segmented profit (non-time series)

Asset portfolio analysis

Market indices-stocks/shares

Net asset value per share

Share price

Profit (various definitional forms)

Shareholders' funds

Measure of market size

Assets (various definitional forms)

Return on sales

Return on capital employed (various definitional forms)

Dividends (various definitional forms)

Capital expenditure

No.

$\%$

Other

$\begin{array}{rr}438 & 30.7 \\ 88 & 6.2 \\ 113 & 7.9 \\ 109 & 7.6 \\ 87 & 6.1 \\ 65 & 4.6 \\ 35 & 2.4 \\ 33 & 2.3 \\ 27 & 1.9 \\ 26 & 1.8 \\ 22 & 1.5 \\ 21 & 1.5 \\ 18 & 1.3 \\ 18 & 1.3 \\ 16 & 1.1 \\ 15 & 1.1 \\ 14 & 1.0 \\ 281 & 19.7 \\ 1,426 & 100.0\end{array}$


Table 4

Type of Graph Used for Key Financial Variables

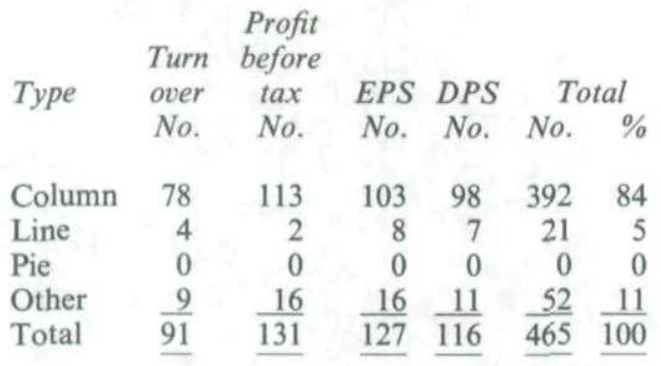

use graphs when performance was above, rather than below, the median. The analysis was restricted to the current year, due to its superiority over the five year period in earlier testing. While the test statistics were again in the expected direction in every case, they were all of lower significance than in Table 5, and most lacked significance at conventional levels (the detailed results are not reported here, but are available from the authors upon request). This analysis indicates that management primarily do not wish to show graphs displaying an absolute decline, and are less concerned with displaying relatively poor performance. It may be, however, that the relevant comparison should be with industry averages, rather than with the average for the corporate sector as a whole.

Turning to measurement distortion, Table 6 shows the incidence of material distortions. A materiality level of $5 \%$ was selected based on the conclusions of Pany and Wheeler's (1989) review of materiality judgements, and Tufte's (1983) view that distortions in excess of $5 \%$ indicate 'substantial distortion, far beyond minor inaccuracies in plotting' (p. 57). A total of 142 graphs ( $30 \%$ of the 465 key financial variable graphs) show material discrepancies - 103 exaggerate, and 39 understate, the trend. The pattern is similar for each of the four key financial variables included in this analysis. Table 7 shows the frequency distribution of the Graph Discrepancy Index scores pooled across the four variables. The mean score over the 465 graphs is $+10.7 \%$. Based on only material distortions, the mean score rises to $+34.3 \%$.

The 142 materially discrepant graphs were reexamined and the causes of discrepancy were identified (two graphs had two causes). These causes are summarised in Table 8. Based on this inspection four observations can be made. First, the cause of the discrepancy is most frequently non-specific, i.e. the graph is simply not drawn in proportion to the underlying numerical values. The absence of a scaled vertical axis and/or grid lines frequently accompanies this type of distortion. Second, in twelve cases the trend in the variable over five years was in the opposite direction to the change in the current year. Under these circumstances the effect of distortion on the portrayal of the company's performance is ambiguous. A non-zero or broken vertical axis will exaggerate an upward trend, but also exaggerate the decline in the final year. We therefore excluded these twelve graphs when testing hypotheses 3 and 4 . Third, we recognise that unfavourable distortions can be caused by graphing difficulties, arising from relatively small magnitudes in the initial year. However to identify and exclude such cases would have involved arbitrary judgements which were not undertaken. Fourth, it can be argued that, where, for example, specific causes of measurement distortion exist which are clearly labelled (or explained by way of a footnote disclosure), misperceptions will not arise. However given our earlier argument concerning the dominance of elementary visual tasks in graphs used for presentation purposes, axes' scales and labels may not be thoroughly read and cognitively processed, and therefore misperceptions will arise. Moreover, we found no inaccuracies explained by way of a footnote. Three examples of graphs showing material measurement discrepancies are given in the Appendix. These examples, drawn from our sample, are illustrative of the most frequent causes of discrepancies.

Hypothesis 3 stated that measurement distortion is likely to give a more, rather than less, favourable portrayal of the company's performance. Of the 130 remaining graphs which were materially distorted, 98 exaggerated an upward trend (favourable), one understated a declining trend (favourable), and 31 understated an upward trend (unfavourable). The hypothesis was tested using the binomial test (Siegel and Castellan, 1988, pp. 38-44). A one-tailed test was very significant $(\mathrm{z}=5.88, \mathrm{p}<0.00001)$, indicating that measurement distortions are likely to portray a more favourable performance. Hypothesis 3 is supported.

Hypothesis 4 concerns the relationship between the company's performance and the effect of the distortion on its portrayal. The median percentage increase over five years was used as a cut-off point for classifying performance as 'good' or 'bad'.? Where the performance of the variable graphed was below the median, $79 \%$ of distortions were favourable; where the performance of the variable being graphed was above the median, $73 \%$ of distortions were favourable. This difference, though in the expected direction, was not signifi-

\footnotetext{
${ }^{7}$ Hypothesis 4 was not tested using the zero cut-off to classify performance as 'good' or 'bad', since only one out of the 142 cases of material discrepancies displayed a 'bad' performance (i.e. a declining trend)
} 


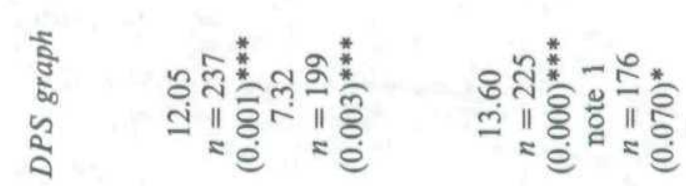

可芯

亲

ङ

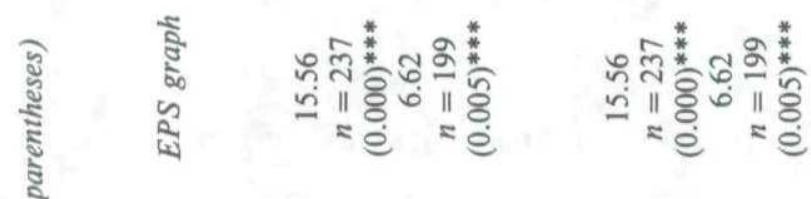

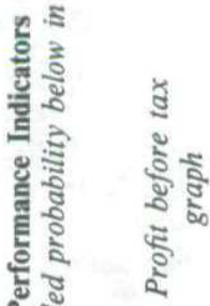

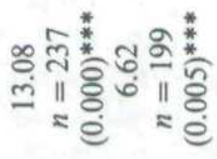

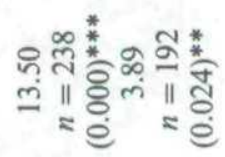

를

ํํㅇ 푬

용

总要

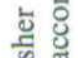

논

독

i.

है

$\frac{3}{n}$

드ㄹㅡㅠ.

跤

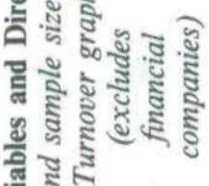

ลู.

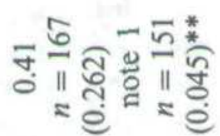

를

융

.

폴

을

등

है

을

ले.

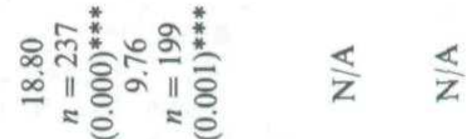

造

衰

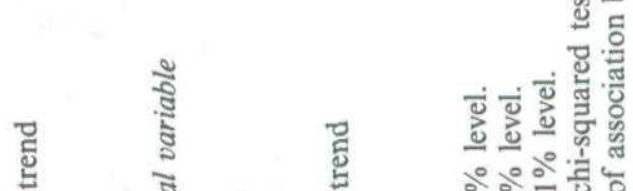

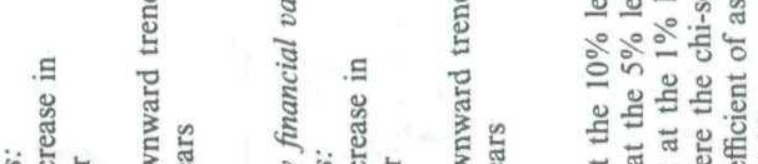

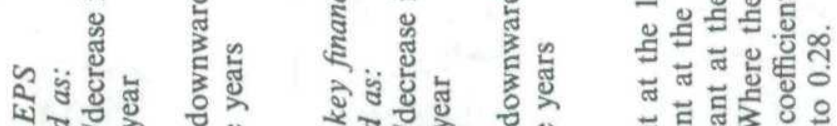

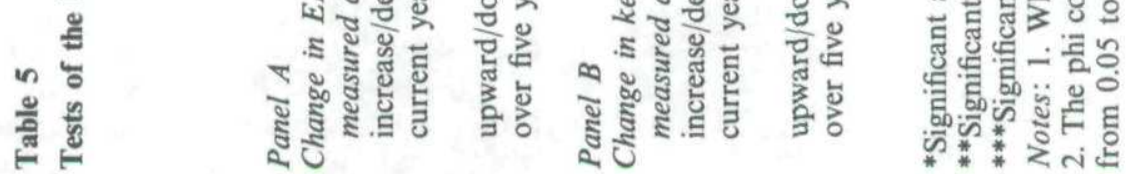
इ

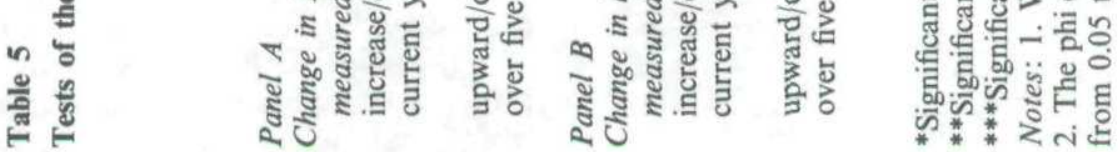


Table 6

Incidence of Materially Discrepant Graphs

Graph Discrepancy Index (GDI)

\begin{tabular}{|c|c|c|c|c|c|c|c|c|c|}
\hline & & & & finan & isl & able & & & \\
\hline Tur & over & befo & $e \operatorname{tax}$ & & & & PS & & tal \\
\hline No. & $\%$ & No. & $\%$ & No. & $\%$ & No. & $\%$ & No. & $\%$ \\
\hline 25 & 27 & 26 & 20 & 27 & 21 & 25 & 22 & 103 & 22 \\
\hline 5 & 6 & 9 & 7 & 14 & 11 & 11 & 9 & 39 & 8 \\
\hline 61 & 67 & 96 & 73 & 86 & 68 & 80 & 69 & 323 & 70 \\
\hline$\overline{91}$ & $\overline{100}$ & $\overline{131}$ & $\overline{100}$ & $\overline{127}$ & $\overline{100}$ & $\overline{116}$ & $\overline{100}$ & $\overline{465}$ & $\overline{100}$ \\
\hline
\end{tabular}

Material exaggeration of trend, i.e. $\mathrm{GDI} \geqslant 5 \%$

Material understatement of trend,

i.e. GDI $\leqslant-5 \%$

No material discrepancy

Total

cant $\left(\chi^{2}=0.211, \mathrm{p}<0.35\right.$ (one-tailed)), and hypothesis 4 is not supported. This lack of significance is perhaps not surprising given our earlier finding that companies with poor performance are less likely to use graphs.

\section{Discussion}

Our results show that $79 \%$ of large UK companies use graphs and most of these companies graph at least one key financial variable. There is strong evidence to suggest that the decision to present graphs of these variables depends upon the company's short-term, i.e. one year, performance. This would seem to furnish additional evidence to support the view that UK companies concentrate on short-term, rather than long-term, performance. A large number of graphs contain material inaccuracies, and a significantly large proportion of these inaccuracies enhance the portrayal of the company's performance, which suggests active manipulation by those responsible for the preparation of

Table 7

Frequency Distribution of Graph Discrepancy Index Scores

$$
\begin{aligned}
& \text { GDI } \leqslant-50 \\
& -50<\text { GDI } \leqslant-25 \\
& -25<\mathrm{GDI} \leqslant-10 \\
& -10<\text { GDI } \leqslant-5 \\
& -5<\text { GDI }<5 \\
& 5 \leqslant \text { GDI }<10 \\
& 10 \leqslant \text { GDI }<25 \\
& 25 \leqslant \text { GDI }<50 \\
& 50 \leqslant \text { GDI }<100 \\
& 100 \leqslant \text { GDI }
\end{aligned}
$$

$\begin{array}{rr}\text { No. } & \% \\ 1 & 0 \\ 4 & 1 \\ 15 & 3 \\ 19 & 4 \\ 323 & 70 \\ 30 & 6 \\ 30 & 6 \\ 15 & 3 \\ 12 & 3 \\ 16 & \underline{4} \\ \underline{465} & \underline{100}\end{array}$

Mean GDI score $(n=465)=+10.7 \%$.

Mean material GDI score $(n=142)=+34.3 \%$. the graphs. This evidence of manipulation of presentation is supportive of, and complementary to, a number of positive accounting studies which indicate that management uses accounting method choices to manipulate the content of financial statements (summarised in Watts and Zimmerman, 1986, ch. 11). It is also consistent with studies which suggest that management manipulates the quality of disclosures (Morton, 1974; Adelberg, 1979).

It is interesting to compare our UK results with those of Steinbart (1989). The general pattern of graph use is remarkably similar. In both countries $79 \%$ of companies use graphs, with the numbers graphing at least one key financial variable varying little (UK, $65 \%$; US, $66 \%$ ), although it should be noted that Steinbart does not include EPS as a key financial variable. The average number of graphs per annual report was, however, found to be somewhat lower in the UK (UK, 5.9; US, 8.0). The incidence of measurement distortion was also lower in the UK. Based on a $10 \%$ materiality threshold (to enable a valid comparison), $20 \%$ of UK graphs show discrepancies above this level compared with $26 \%$ in the US. However the mean Graph Discrepancy Index scores were highly comparable (UK, $+10.7 \%$; US, $+11 \%$ ). In both countries the distortions tended to portray the company's performance more favourably. Although the majority of material distortions were overstatements of a rising trend, 31 of the 142 distorted graphs understated a rising trend. Apart from random graphing inaccuracies there may be two explanations for this. First, positive accounting theory suggests that organisations with high political costs, relative to other contracting costs, will prefer to understate an upward trend. Investigation of this issue is outside the scope of the present study. Second, in some cases with steeply rising results, unfavourable distortions can be caused by graphing difficulties arising from relatively small magnitudes in the initial year.

When interpreting our results it should be remembered that we used 1989 annual reports. This 
Table 8

Cause of Materially Discrepant Graphs of Key Financial Variables

Cause

$\begin{array}{cl}\text { No. of } & \text { No. of } \\ \text { companies } & \text { graphs }\end{array}$

Non-zero vertical axis

Broken vertical axis

Non-arithmetic scale

Negative value truncated

Graphic distance not in direct proportion

to the numerical values being represented

Total

companies

graphs

6

17

$2 \quad 2$

$\begin{array}{ll}2 & 6 \\ 1 & 1\end{array}$

$69 \quad 118$

was a year which saw the culmination of a period of general growth in corporate profits. In such an environment, the incidence of all forms of distortion can be expected to be minimised, since firms will already be reporting essentially favourable messages.

\section{Conclusion}

This paper conducts an empirical study of the use and abuse of financial graphs in large UK companies. Its main findings are that (1) graphs are widely used, (2) companies with 'good' performance are significantly more likely to use graphs, (3) measurement distortion is significant, and (4) the effect of measurement distortion is generally to portray the company's performance more favourably.

We therefore conclude that financial graphs are not fulfilling their potential for enhancing effective communication. The highly significant association between the incidence of graph use and a favourable recent performance by the company, combined with the tendency for measurement distortion to portray the company's performance more favourably, suggests that companies are actively manipulating graphs contained in annual reports. This manipulation undermines the neutrality of financial statements, which has long been recognised as an essential requirement of financial reporting (e.g. AICPA, 1973; ASSC, 1975; and IASC, 1989).

These conclusions have important policy implications. Currently there is no specific professional auditing requirement with respect to graphs. Auditors are merely required to ensure that "the credibility of the financial statements is not undermined', in accordance with the general requirement contained in the Auditing Guideline 'Financial Information Issued with Audited Financial Statements' (1985). Given the high level of graph use, and the obvious difficulties in assessing whether or not credibility has been undermined, auditors' responsibilities should be made more explicit. In addition, these issues are currently not addressed by accounting standards. We therefore believe that there is a need to develop specific guidelines which would enable both preparers and auditors to judge whether graphs portray financial information in an unbiased way. Such guidelines, covering selectivity in the use of graphs, and measurement and presentational distortion, could be developed from modern statistical graphics theory and would be premised upon empirical studies into the actual practices of companies in their corporate financial statements. This paper, by investigating the use of graphs by UK companies, and by documenting evidence of the incidence of measurement distortion in key financial graphs, represents in our view an important first stage in the development of such guidelines.

\section{References}

Accounting Standards Steering Committee (1975), The Corporate Report.

Adelberg, A. H. (1979), 'Narrative Disclosures Contained in Financial Reports: Means or Communication of Manipulation?, Accounting and Business Research, Summer, pp. $179-189$.

American Institute of Certified Public Accountants (1973), Objectives of Financial Statements, Report of the Study Group on Objectives of Financial Statements.

Anderson, A. V. (1983), Graphing Financial Information, National Accounting Association.

Auditing Practices Committee (1985), Financial Information Issued with Audited Financial Statements, Auditing Guideline.

Birnberg, J. G., Turopolec, L. and Young, S. M. (1983), 'The Organizational Context of Accounting', Accounting, Organizations and Society, Vol. 8 (2/3), pp. 111-129.

Blocher, E., Moffie, R. P. and Zmud, R. W. (1986), 'Report Format and Task Complexity: Interaction in Risk Judgements', Accounting, Organizations and Society, Vol. 11(6), pp. $457-470$.

Carsberg, B. (1985), 'Financial Reporting in the USA', in Comparative International Accounting, (eds) Nobes, C. W. and Parker, R. H., Philip Allan/St. Martins Press, pp. 13-43.

Cleveland, W. S. (1985), The Elements of Graphing Data, Wadsworth.

Cleveland, W. S. and McGill, R. (1987), 'Graphical Perception: The Visual Decoding of Quantitative Information on Graphical Displays of Data', Journal of the Royal Statistical Society, Vol. 150(3), pp. 192-229. 
Cunningham, E. (1990), 'Up There with the Best-and Deservedly So', Accountancy Age, 10 May.

Davis, L. R. (1989), 'Report Format and the Decision Maker's Task: An Experimental Investigation', Accounting, Organizations and Society, Vol. 14(5/6), pp. 495-508.

DeSanctis, G. and Jarvenpaa, S. L. (1989), 'Graphical Investigation of Accounting Data for Financial Forecasting: An Experimental Investigation', Accounting, Organizations and Society, Vol. 14(5/6), pp. 509-525.

Griffiths, I. (1986), Creative Accounting: How to Make Your Profits What You Want Them to Be, Sidgwick and Jackson.

Hines, R. D. (1982), 'The Usefulness of Annual Reports: the Anomaly between the Efficient Markets Hypothesis and Shareholder Surveys', Accounting and Business Research, Autumn, pp. 296-309.

Holmes, G. (1984), 'How to Present Your Message Graphically', Accountancy, April, pp. 64-71.

Huff, D. (1954), How to Lie with Statistics, Penguin.

Hussey, R. (1990), 'Accuracy with a Dash of Panache', AA Magazine, October, pp. 18-25.

International Accounting Standards Committee (1989), Framework for the Preparation and Presentation of Financial Statements.

Jarett, I. M. (1983), Computer Graphics and Reporting Financial Data, John Wiley.

Johnson, J. R., Rice, R. R. and Roemmich, R. A. (1980), 'Pictures that Lie: the Abuse of Graphs in Annual Reports', Management Accounting, October, pp. 50-56.

Kaplan, S. E. (1988), 'An Examination of the Effect of Presentation Format on Auditors' Expected Value Judgements', Accounting Horizons, September, pp. 90-95.

Korol, J. K. (1986), 'Graphical Perception and the Representation of Financial Information', Georgia Journal of Accounting, Vol. 7, pp. 147-157.

Kosslyn, S. M. (1985), 'Graphics and Human Information Processing', Journal of the American Statistical Association, September, pp. 499-512.

Kosslyn, S. M. (1989), 'Understanding Charts and Graphs', Applied Cognitive Psychology, Vol. 3, pp. 185-226.

Lea, R. (1989), 'ConsGold Ad Puts Ernst in Breach of FSA Rules', Accountancy Age, 16 March.

Leach, R. (1985), 'Anatomy of a Takeover Bid', Accountant, 18 April.

Leach, R. (1988), 'Let the Message Dictate the Medium', Accountancy, January, pp. 93-94.

Lee, T. A. and Tweedie, D. P. (1975), 'Accounting Information: An Investigation of Private Shareholder Usage', Accounting and Business Research, Autumn, pp. 280-291.

Lee, T. A. and Tweedie, D. P. (1977), The Private Shareholder and the Corporate Report, ICAEW.

Lewandowsky, S. and Spence, I. (1989), 'The Perception of Statistical Graphs', Sociological Methods and Research, Vol. $18(2 / 3)$, pp. $200-242$.

Libby, R. and Lewis, B. L. (1977), 'Human Information Processing Research in Accounting: The State of the Art', Accounting, Organizations and Society, Vol. 2(3), pp. $245-268$.

Martin, D. M. (1989), How to Prepare the Annual Report, Fitzwilliam Publishing.
Mason, J. (1985), 'A Wealth of Information', Accountant, pp. 14-15.

Morton, J. R. (1974), 'Qualitative Objectives of Financial Accounting: A Comment on Relevance and Understandability', Journal of Accounting Research, Autumn, pp. 288-298.

Nobes, C. W. (1987), 'Financial Reporting in the USA: Why and How it Differs', Management Accounting, May, pp. 16-17.

Paivio, A. (1974), 'Spacing of Repetitions in the Incidental and Intentional Free Recall of Pictures and Words', Journal of Verbal Learning and Verbal Behaviour, Vol. 13, pp. 497-511.

Pany, K. and Wheeler, S. (1989), 'Materiality: An Inter-Industry Comparison of the Magnitude and Stabilities of Various Quantitative Measures', Accounting Horizons, Vol. 3(4), December, pp. 71-78.

Schmid, C. F. and Schmid, S. E. (1979), Handbook of Graphic Presentation, 2nd ed., Ronald Press.

Schmid, C. F. (1983), Statistical Graphics: Design Principles and Practices, John Wiley/Interscience.

Siegel, S. and Castellan, N. J. (1988), Nonparametric Statistics for the Behavioral Sciences, 2nd. ed, McGrawHill.

Simkin, D. and Hastie, R. (1987), 'An Information-Processing Analysis of Graph Perception', Journal of the American Statistical Association, Vol. 52, pp. 454465.

Steinbart, P. J. (1989), 'The Auditor's Responsibility for the Accuracy of Graphs in Annual Reports: Some Evidence of the Need for Additional Guidance', Accounting Horizons, September, pp. 60-70.

Stock Exchange (1989), Quality of Markets and Companies Book, Brown and Shipley.

Sugden, A. (1989), 'Public Relations: The Conflict with "True and Fair"', Accountancy, September, pp. 100-102.

Sullivan, J. J. (1988), 'Financial Presentation Format and Managerial Decision Making: Tables Versus Graphs', Management Communication Quarterly, Vol. 2(2), pp. 194-216.

Taylor, B. G. and Anderson, L. K. (1986), 'Misleading Graphs: Guidelines for the Accountant', Journal of Accounting, October, pp. 126-135.

Tufte, E. R. (1983), The Visual Display of Qualitative Information, Graphic Press.

Tweedie, D. P. and Whittington, G. (1990), 'Financial Reporting: Current Problems and their Implications for Systematic Reform', Accounting and Business Research, Vol. 21, pp. 87-102.

UBS Phillips and Drew (1991), Accounting for Growth, Report, January.

Watts, R. L. and Zimmerman, J. L. (1986), Positive Accounting Theory, Prentice-Hall International.

Wilkins, R. M. and Lennard, A. C. (1988), 'Historical Summaries', in Financial Reporting 1987/88, Skerratt, L. and Tonkin, D. (eds), ICAEW, pp. 67-93.

Wood, D. (1990), 'Wanted: a Realistic Historical Summary', Accountancy Age, 18 January.

Wright, W. F. (1989), 'Graphical Displays and Improved Decision Making' in Computers and the Social Sciences, Garson, G. D. and Nagel, S. (eds), JAI Press. 
Appendix. Illustrative Examples of Measurement Discrepancy

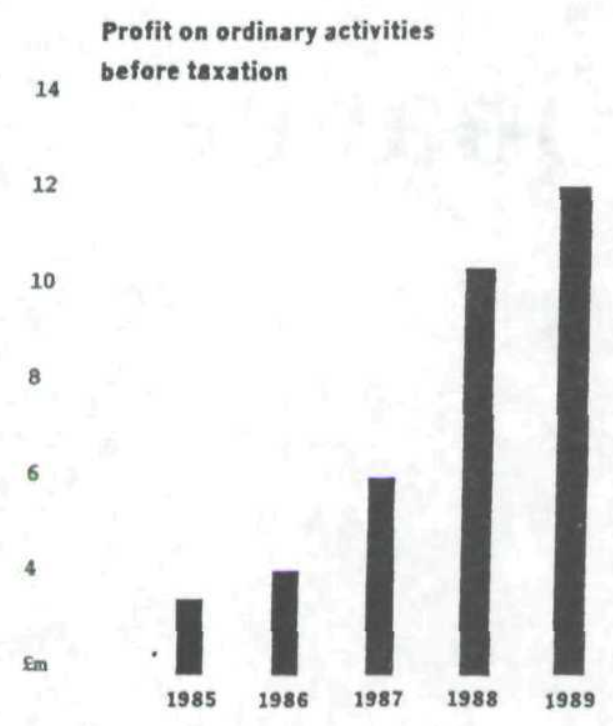

Source: Grampian Holdings plc, Annual Review and Accounts, 1989.

This graph shows a measurement discrepancy of $+112 \%$, caused by the use of a non-zero axis.

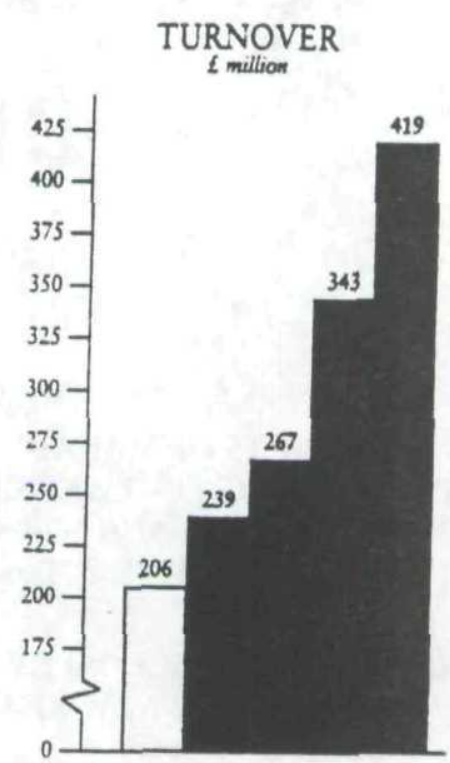

Source: Higgs and Hill plc, Report and Accounts, 1989.

This graph shows a measurement discrepancy of $+161 \%$, caused by the use of a broken axis.

\section{Dividends per share (pence)}

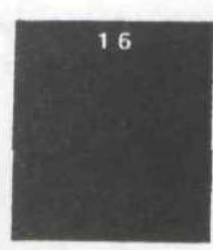

87

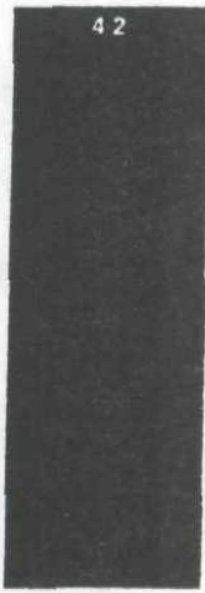

89

\section{9}

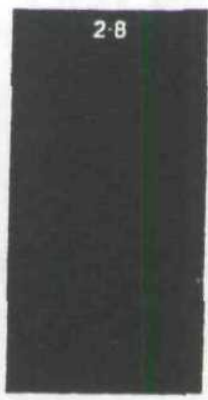

88

Source: Midsummer Leisure plc, Annual Report and Accounts, 1989.

This graph shows a measurement discrepancy of $+86 \%$. This is not attributable to any specific cause (the graph is simply not drawn in proportion to the underlying numerical values). 
Copyright of Accounting \& Business Research is the property of Croner.CCH Group Limited and its content may not be copied or emailed to multiple sites or posted to a listserv without the copyright holder's express written permission. However, users may print, download, or email articles for individual use. 